$1991-9$

\title{
Case-Based Reasoning and Risk Assessment in Audit Judgment
}

Eric L. Denna

James V. Hansen

Rayman D. Meservy

Brigham Young University, rayman_Meservy@byu.edu

Larry E. Wood

Follow this and additional works at: https://scholarsarchive.byu.edu/facpub

Part of the Accounting Commons, and the Management Information Systems Commons

\section{BYU ScholarsArchive Citation}

Denna, Eric L.; Hansen, James V.; Meservy, Rayman D.; and Wood, Larry E., "Case-Based Reasoning and Risk Assessment in Audit Judgment" (1991). Faculty Publications. 3233.

https://scholarsarchive.byu.edu/facpub/3233

This Peer-Reviewed Article is brought to you for free and open access by BYU ScholarsArchive. It has been accepted for inclusion in Faculty Publications by an authorized administrator of BYU ScholarsArchive. For more information, please contact ellen_amatangelo@byu.edu. 
CASE-BASED REASONING

AND RISK ASSESSMENT

IN AUDIT JUDGMENT

Eric L. Denna, Ph.D.

BITNET DENNAE@BYUVAX

James V. Hansen, Ph.D.

BITNET HANSENJ@BYUVAX

Rayman D Meservy, Ph.D.

BITNET MESERVYR@BYUVAX

Larry E. Wood, Ph.D.

BITNET WOODL@BYUVAX

AI Research Lab in Accounting Judgment

at

The School of Accountancy

and

Information Systems

Brigham Young University

19 April, 1991

Presented at the

3rd International Symposium

on

Expert Systems

in Business, Finance, and Accounting

Laguna Niguel, California

26-28 September, 1991 


\begin{abstract}
The purpose of this paper is to describe the results of an effort to utilize Case Based Reasoning (CBR) to model a specific audit judgment task. To date most efforts to develop computational models of audit judgment have used strictly rule-based representation methods. Some researchers have recently adopted more robust structures to model the auditor domain knowledge. Although these recent efforts to extend the representation methods appear to be more accurate descriptions of auditor reasoning and memory, they still lack a comprehensive theory to guide the development of the model. A commonly encountered phenomenon in audit judgment is for an auditor to compare the current case to similar previous experiences. Others have proposed a model for this type of judgment in other expert judgment domains. This model has become known as case-based reasoning (CBR). This study describes our initial efforts to utilize caśe-based reasoning to model a specific audit judgment task.
\end{abstract}




\section{INTRODUCTION ${ }^{1}$}

In the recently revised Research Opportunities in Auditing: The Second Decade, Ashton, et al [1988], emphasized the need for descriptive studies of audit judgment utilizing computational modeling techniques commonly used in artificial intelligence research. Specifically, they note:

...the ultimate benefit of descriptive research in audit decision making is a greater understanding of how decisions are made so that decision improvement can be facilitated. The increasing use of decision support and expert systems in auditing makes clear that this research is linked to practice through a technology bridge...there is an important link between descriptive studies of expertise and the development and use of expert systems. As Johnson [1983] points out, expert systems based on authentic accounts of expert performance (i.e., what the expert actually does) are likely to be most effective and acceptable to decision makers (p. 131).

Since Dungan's [1983] initial work utilizing the computer to model accounting judgment tasks, several research projects have provided various computational models of expert audit judgment (e.g. Hansen and Messier [1986], Meservy, Bailey, and Johnson [1986], and Steinbart [1987], Graham, et al [1990]). Recently, Denna, Hansen, and Meservy [1991] evaluated the progress of research in developing computational models of expert audit judgment. Among the observations made, they noted that AI research in auditing has suffered from many of the same weaknesses found in AI research in general.

These weaknesses include the following:

1. Restricted representation methods for accurately modeling expert judgment.

2. Restricted use of the knowledge in the computational model for the specific reasoning process modeled.

3. Restricted models of expert domain knowledge and its interaction with the reasoning process.

4. Restricted ability to learn from experiences.

To address some of these limitations Denna, Hansen, and Meservy [1991] called for research efforts in three areas to answer the criticisms listed above:

1. Knowledge acquisition - while many have attempted to devise more efficient methods of extracting expert knowledge, attention needs to focus on more effective ways of extracting expert knowledge. The focus should be on developing methods for developing unbiased descriptions of expert audit judgment.

1 Our thanks to several participants of The Third Annual Symposium on Expert Systems in Business, Finance, and Accounting held at Marina Del Mar, CA., Sept. 22-27, 1990, for helpful comments regarding this work. 
2. Knowledge representation - past efforts to model audit judgment has focused on the use of rule-based reasoning. While rule-based reasoning may be appropriate for some types of audit reasoning, it certainly does not appear to be appropriate for many types of audit reasoning. Particularly, rule-based reasoning does not appear to be an accurate description of audit judgment based upon utilizing prior audit experience. In order to eventually provide a complete model of expert audit judgment, the focus should be on developing the most appropriate representation methods for each the types of reasoning utilized by expert auditors.

3. Model validation - eventually, research will be needed to both propose and perform effective evaluations of competing models of audit judgment. Once again, the attention should focus on assessing the representational faithfulness of the model based upon the knowledge documented during the knowledge acquisition phase of a project.

In this paper, we will focus on the issue of representing auditor memory and reasoning. Notwithstanding recent advances by audit judgment researchers in proposing new methods for representing auditor judgment (see, Selfridge and Biggs [1988], Peters [1989], and Denna [1989]) it appears we still do not have appropriate methods for representing certain types of auditor judgment. Specifically, representation methods utilized to this point in modeling auditor judgment do not appear to accurately model judgment based primarily upon reasoning from prior experience.

There is evidence and argument that a case-based reasoning model offers a more faithful representation of the way that humans really solve problems when utilizing prior similar experiences. Riesbeck and Schank [1989] assert that case-based reasoning (CBR) is the essence of how human reasoning really works. They argue that an individual's knowledge is the collection of experiences (cases) acquired first hand or from others who have had similar experiences.

Riesbeck's and Schank's basic proposition is that expert decision makers do not typically reason from first principles; that is to say, they do not reason about each problem as though it were unique. Instead, experts attempt to find a prior successful solution which is the most closely related to the problem at hand and then attempt to adapt the prior solution to the current problem. Therefore, experience plays a central role in expert reasoning by changing the knowledge used to form a hypothesis. This method of reasoning helps the expert learn by enabling generalization from successful experiences. Additionally, experts also learn from other similar experiences which have been handled unsuccessfully. Secondly, previous cases (termed exemplars) recovered from memory during hypothesis generation help direct the creation and ranking of new hypotheses.

In this paper we proceed from the premise that case-based reasoning is a potentially rich method of modeling many instances of expert audit judgment. Additionally, we assume that modifying the knowledge content of a computational model's memory as new cases are analyzed allows a form of learning to be incorporated in the model. These capabilities seem particularly suited to the audit arena in which expertise seems to reflect learning that has taken place in evaluating a large number of audit engagements [Biggs, et. al., 1988]. The research described in this paper focuses on our initial findings using CBR to model expert audit judgment. Particularly, we were interested in seeing if indeed using CBR could help to address some of the limitations listed at the beginning of this paper regarding modeling of expert judgment. 
The remainder of the paper proceeds as follows. Section 2 describes in greater detail the concept of CBR proposed by Riesbeck and Schank [1989]. Section 3 describes an application of CBR to a specific audit judgment task involved in determining the likelihood of material error. Finally, Section 4 offers some concluding remarks and proposes various potential extensions to the work described in this paper.

\section{CASE-BASED REASONING}

A commonly observed phenomenon associated with expert judgment is that experience appears to foster the refinement of reasoning processes and knowledge in two significant ways. First, successful experiences reinforce previously-utilized hueristics and hypotheses. Meanwhile, failures prompt analysis of the reasoning and knowledge used originally and modification of faulty hueristics and knowledge. Second, individual experiences act as exemplars upon which to base later decisions. Reference to previous cases serves to guide later hypothesis generation and decision making.

The implication of these two observations is that a model of expert reasoning demonstrating the use of cases should include the following characteristics:

1. The model should be able to find a case which is similar to the problem at hand.

2. The model should be able to learn in a sense by adapting prior similar cases to the situation at hand and storing them for use in the future.

\section{$\underline{\text { Recognizing Similar Situations }}$}

Recognizing the similarities between two instances in a problem domain is central to case-based reasoning. Kolodner [1984] has suggested the following criteria for establishing that two cases are similar:

1. Two cases are similar if they are represented by the same representational schema. In the case of an audit, for example, the auditor must render a qualified or unqualified opinion. The series of test results leading to the same opinion would exemplify the same representational schema.

2. They share salient and unnaccounted-for features. For example, a problem may be observed which is not predicted by the representational schema. These symptoms may sometimes be irrelevant--hence the requirement for saliency.

3. A feature is said to be salient if it can make a schema-related prediction.

Without an ability to reason from prior cases, a computational model would not provide a case-based reasoning approach to problem solving. Additionally, the model would need to demonstrate an ability to learn from prior experience.

\section{Learning}

Three kinds of learning happen in the course of case-based reasoning: 
1. Integration of a new case into memory

\section{Similarity-triggered generalization}

\section{Failure-triggered generalization.}

Learning is integrated through the use of a dynamic memory in which new instances are integrated into the memory as they are being processed. An experience added to memory contributes to better problem solving in several ways. First, if problem solving has been complex and time consuming, utilizing the prior case should be more efficient than reasoning from first principles. Second, if a problem is encountered while processing a particular experience, the processing difficulty should be pointed out whenever the experience is referred to in the future. Third, if a solution to a previous problem while using a prior experience has been found in the course of solving that or other problems, the model should prevent the same problem from recurring in the future.

As discussed in Riesbeck and Schank [1989], CBR depends on a memory organization which can be used to store and retrieve knowledge, including cases. Their method (which we adopted for this project) is to use a frame representation called Memory Organization Packages (MOPS). Analysis, storage, retrieval, and adaptation of cases is made possible through two kinds of MOPs, abstractions and instances. As new cases are processed, the organization of memory is changed to represent what has been "learned" that will improve system performance in the future. See Riesbeck and Schank [1989] for details.

In a nutshell, the CBR process is as follows. First, the process identifies various types of cases during the evaluation of a new case by traversing the network of prior experiences. Second, the process identifies the representational schema (abstraction) which most closely resembles the new zase. Third, the process identifies features which differentiate the new case from the nearest abstraction. Finally, the process traverses the indices which correspond to the new case and are associated with an abstraction.

\section{Case-Based Reasoning and the audit Environment}

Rule-based systems have typically dominated work in modeling audit judgment tasks [cf. Denna, et. al., 1991]. This may be due in part to the fact that the rule-based paradigm was widely used in early work on expert systems. It may also be true that they are well suited to certain kinds of audit activities.

Nonetheless, knowledge acquisition is nearly always difficult in building rule-based systems for auditing. Audit experts have not found it easy to list the sequence of rules, which may number in the hundreds, used to solve problems. Neither do rule-based systems provide a memory that relates similar occurrences. Messier and Hansen [1988] found numerous instances in which the auditors solved problems by referencing previous situations. finalyy, rule-based systems provide little capability to extract information from their experience to improve their problem-solving ability.

These difficulties are more easily handled by case-based systems. the knowledge engineer does not have to extract from the expert a set of rules which are difficult for the expert to specify. Experts are much more comfortable with specifying situations which are familiar. Case-based systems are oy design capable of relating past experience to current observations. Moreover, they have the 
capability of dynamically upgrading memory, based on new information, so as to improve problem-solving.

\section{AN EXAMPLE CBR IN AUDIT JUDGMENT}

The question to be asked is, "Do auditors appear to utilize case-based reasoning while performing audit judgment tasks?" Consider the following simplified example roughly based on the work of Mutchler [1985]. Suppose an auditor, while examining an organization's financial records, makes the following observations:

1. The ratio (cash flow)/(total debt) is negative.

2. The ratio (net worth)/(total liabilities) is negative.

3. The earnings trend is down.

From prior experience, the auditor quickly realizes that these circumstances typically require the rendering of a qualified opinion. By this we mean that the opinion is conditional and cautionary. For the novice auditor this might be considered to be the basic diagnosis as shown at the top of Figure 1.

FIGURE 1 - TRAVERSING CASE-BASED MEMORY

Now, suppose that another firm is audited which has characteristics 1-3, above, but the following information is also revealed: 
4. Sales have increased $10 \%$ over last year.

5. An unprofitable division was sold at the end of the year.

This situation is also depicted in Figure 1. Items 1-3 are presented as a schema which represents a generalized episode. Individual audit findings are indexed off a generalized episode by their differentiating features--in this case items 4-5. Using issuance of a qualified opinion as the result of a generalized episode, the example is differentiated from other instances of qualified opinions by the fact that there are offsetting favorable developments. If additional cases exhibiting the characteristics 4-5 are later observed, a new generalized episode may be created at that index point with the supporting cases as well.

Another example of what appears to be case-based auditor reasoning is during the auditors assessment of the likelihood of material error. The assessment of the likelihood of material error occurs during the audit planning process which is illustrated in Figure 2.

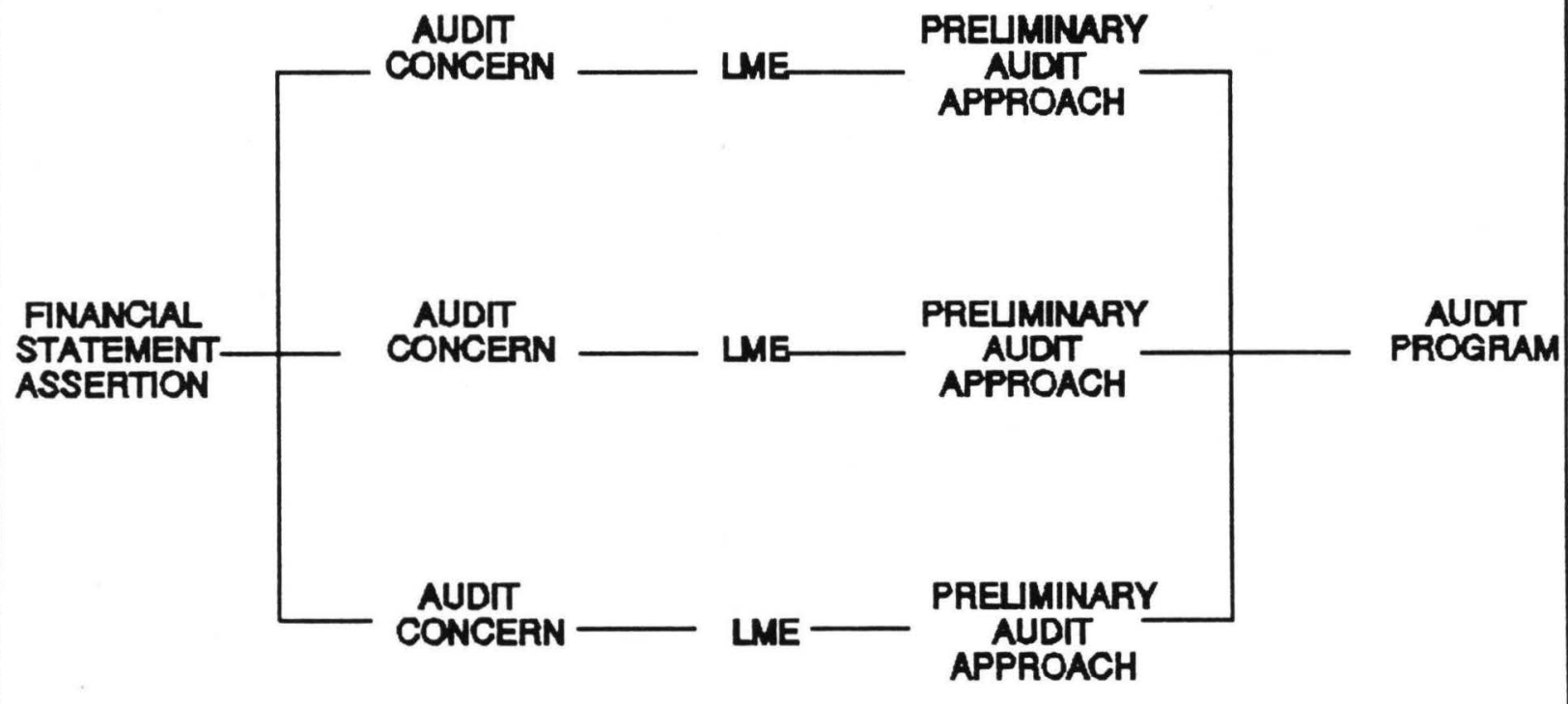

Figure 2 - AUDIT PLANNING JUDGMENT TASKS

(Source: Denna [1989]) 
The objective of the planning process is to develop an audit plan. Accomplishing this overall objective requires a number of intermediate reasoning steps which are also identified in Figure 2. Of those identified in Figure 2, the likelihood of material error appears to require significant audi! judgment expertise (see Denna [1989]).

A critical part of the likelihood of material error assessment involves determining the impact of changes in the client operating environment on the client's financial assertions and thereby the likelihood of material error (LME). When faced with changes in the client operating environment, the auditor will search for similar prior experiences in order to assess the impact of the changes on the client's financial assertions. Specifically, the auditor looks at the impact of the change on Net Income. The impact of the change in the operating environment then becomes a component used in the overall assessment of the likelihood of material error (see Denna [1989] for a more complete model of the LME assessment process). Our interest is in applying the use of a case-based reasoning approach to this one portion of the general LME assessment process. Additionally, we hope to determine whether the CBR approach provides an adequate description of the use of experience by expert audit decision makers involved in the LME assessment process.

This project focused specifically on modeling a single auditor's assessment of the likelihood of material error related to Net Income. We also focused on cases related to a single retail grocer for whom the auditor had performed eight annual audits.

\section{APE-II: A CBR MODEL OF THE LME ASSESSMENT PROCESS ${ }^{2}$}

Our initial efforts to apply case-based reasoning involved adapting Bain's [1986] Micro-Judge to model the audit judgment performed in process 3 of Figure 3. Micro-Judge is a model of two members of the Connecticut Superior Court. In Micro-Judge, each object in memory (whether domain knowledge or a procedure) is stored as a MOP (Schank [1982]). Each experience consists of a series of MOPs which are temporally related and which also trigger various procedures for adapting similar experiences to the current situation in order to render a judgment.

APE-II was implemented using code from Micro-Judge (see Riesbeck and Schank [1989]) for the basic algorithms of CBR and then developing MOPs and functions for our audit task, specifically. As described in Reisbeck and Schank, there are basically two types of MOPs: abstractions and instances. Instances represent specific cases, individual events, or objects, whereas abstractions are generalized versions of instances or other abstractions. The MOPs are organized in a hierarchy by links, which determine what information is available to a reasoner and when. Instance MOPs inherit characteristics and constraints from their abstractions. The constraints can also be used to check "legal" values for the events of a case and their participants. Finally, the abstraction hierarchy can be used to retrieve cases similar to the one being analyzed. Because the MOPs are domain-specific, they must be created for each domain in which the system is to reason.

2 Because this work is an extension of earlier work by Denna [1989] which developed a model of auditor reasoning named Auditor Reasoning and Planning (APE), we chose to call the current project APE-II. 
Figure 3 - LME REASONING PROCESS

(Source: Denna [1989])

For the present study, each case of a typical retail grocery operations was conceptualized as a frame with "slots" for a client, a change in inventory (e.g. stable, increase, decrease), a series of operating events each consisting of an operation (e.g. order inventory, receive inventory), an internal agent (e.g., buyer, dock worker) and an external agent (e.g., vendor, trucker), the direction of change in net income, and the degree of change in net income. The latter two slot values are determined by the system in a preliminary analysis of each new case. As each case is read into the system, an 
instance MOP is created with each of the values for slots linked to the abstraction hierarchy. The hierarchy is shown in Figure 4.

In addition to the various MOPs, we also developed an adaptation method used to analyze the current case. The adaptation method focused primarily on the effect of the current case on the company's net income. The analysis of the effect on Net Income involved the use of various functions which traversed the event MOPs to determine whether Net Income would be higher or lower than the typical amount for the company.

Our test of the adequacy of our model was quite similar to that of Bain [1986] in that we ran three cases through our system. The first case provided a very typical description of operations for a retail grocer. The other two cases each described a strike: the first an employee strike and the second a truckers strike. In order to assess the risk, APE-II performed the following:

1. Retrieve standard description of grocer operations - the first task involves retrieving the typical description of the grocer operations. In addition, APE-II also retrieves the expected Net Income percentage of sales, and the typical LME judgment (High risk, Medium risk, or Low risk) for the inventory phase of operations. This knowledge is stored in a series of MOPS for the particular client and industry.

2. Analyze new case - this step involves analyzing a new situation confronting the auditor focusing on changes in inventory related operations. Basically, APE-II focuses on determining whether Net Income might change given the new inventory operations. The 
analysis involves identifying the significance of the changes in inventory operations and the resulting impact on Net Income.

3. Render LME judgment - having determined the impact of the case on Net Income, APE-II then determines the effect of this one component on the LME. The result is an LME judgment higher, lower, or the same as the standard expectations.

4. Store the new case - after analyizing the new case, its details are stored along with its impact on Net Income expectations and the resulting LME judgment. The newly stored case information is then available for use with the next case.

APE-II was tested by having it assess the impact of two new cases on Net Income and the LME judgment. The first case involved the impact of a truckers strike on the grocer's net income and LME. The second case involved the impact of an employee strike. In the first case, APE-II determined that net income would likely decrease substantially thereby causing a similar change in the LME relating to the inventory balances. The primary reason for the expected drop in net income was the inability of the grocer to find substitute distribution lines for receiving inventory.

In the second case, APE-II determined the employee strike would cause a marginal decrease in net income and LME would be somewhat higher. The primary reason for this outcome was the ability of the grocer to find substitute labor for striking employees.

\section{CONCLUSIONS AND EXTENSIONS}

From this initial test of CBR in modeling expert auditor behavior, we have concluded the following:

1. Although preliminary in nature, CBR models seem an appropriate representation for portions of expert auditor reasoning involving prior experience.

2. CBR provides a critical representation method in working toward the development of a more complete model of auditor reasoning. CBR should be viewed as yet another valuable method for representing certain characteristics of expert auditor reasoning.

As far as extensions to the current project, we would propose the following research efforts:

1. Identify audit judgment tasks which appear to involve CBR. For example, Akresh, Loebbecke and Scott [1988] recently identified a number of audit judgment tasks which auditors perform. A valuable contribution for audit judgment researchers would be to study each of the tasks identified by Akresh, et al [1988] to determine the nature of the auditor memory and the types of reasoning involved in each task.

2. Test the use of CBR in other audit judgment tasks which require the use of prior experiences. For example, we would expect prior experience to play a significant role in judgments dealing with accepting or rejecting new clients, establishing terms for engagements, performing analytical procedures, developing audit plans, reviewing financial statements, and others. Audit judgment certainly appears to be a fruitful judgment area for testing the use of CBR computational models. 
3. Determine ways in which CBR can be integrated with other forms of reasoning represented by rule or frame-based reasoning. Again, we believe CBR to be another method for representing audit judgment tasks with certain specific behaviors.

Overall, we are encourage by the results of this initial effort to utilize CBR as a method for representing expert auditor reasoning. 


\section{REFERENCES}

Akresh, A. D., Loebbecke, J.K., and Scott, W.R., "Audit Approaches and Techniques," in $\underline{\text { Research }}$ Opportunities in Auditing: The Second Decade, A. R. Abdel-Khalik and I. Solomon, eds., American Accounting Association, 1983, pp. 14-55.

Ashton, R. H., D.N. Kleinmuntz, J. B. Sullivan, and L. A. Tomassini, "Audit Decision Making," Research Opportunities in Auditing: The Second Decade, A. R. Abdel-Khalik and I. Solomon, eds., American Accounting Association, 1983, pp. 95-132.

Bain, W.M., "Case-Based Reasoning: A Computer Model of Subjective Assessment," unpublished Ph.D., dissertation, Yale University, 1986.

Denna, E.L., "Auditor Memory and Determining the Likelihood of Material Error: A Computational Model," unpublished Ph.D. dissertation, Michigan State University, 1989.

Denna, E.L., J.V. Hansen, and R. Meservy, "Development and Application of Expert Systems in Audit Services," Transactions on Knowledge and Data Engineering, (forthcoming 1991).

Dungan, C, "A Model of An Audit Judgment In The Form of An Expert System," unpublished Ph.D. dissertation, University of Illinois, 1983.

Graham, L., J. Damens, and G. Van Ness, "Developing Risk Advisor ${ }^{\text {SM. }}$ An Expert System for Risk Identification," presented at the USC Audit Judgment Symposium, Feb. 1990.

Hansen, J.V., and W. F. Messier, "A Preliminary Investigation of EDP-XPERT," Auditing: A Journal of Practice and Theory, Fall 1986, pp. 109-123.

Kolodner, J. Retrieval and Organizational Strategies in Conceptual Memory, Lawrence Erlbaum Associates Publishers, 1984.

Meservy, R., A.D. Bailey, and P. Johnson, "Internal Controls Evaluation: A Computational Model of the Review Process," Auditing: A Journal of Practice and Theory, Fall 1986, pp. 44-74.

Mutchler, J., "A Multivariate Analysis Of The Auditor's Going-Concern Opinion Decision," Journal of Accounting Research, Fall, 1985, pp. 668-682.

Peters, J., "A Knowledge Based Model of Inherent audit Risk assessment," unpublished Ph.D. dissertation, University of Pittsburg, 1989.

Riesbeck, C.K., and R.C. Schank, Inside Case-Based Reasoning, Lawrence Erlbaum Associates Publishers, 1989.

Schank, R.C., Dynamic Memory: A Theory of Learning in Computers and People, Cambridge University Press, 1982. 
Selfridge, M., and S. Biggs, "GCX, A computational Model of the auditor's Going-Concern Judgment," paper presented at the USC Symposium on Expert Systems and Audit Judgmen* (February, 1988).

Steinbart, P. "The Construction of a Rule-Based Expert System as a Method for Studying Materiality Judgments," The Accounting Review, January 1987, pp. 97-116. 
Normal

schema

differences :

\section{Diagnostics}

1. (cash flow) / (total debt) $<0$

2. (net worth) / (total liabilities) < 0

3. earnings trend down

\section{Decision}

Qualified opinion

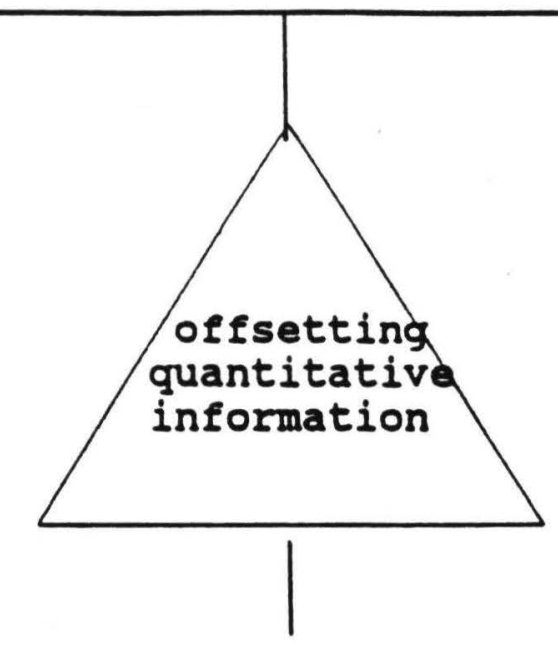

improving

Einancial

trends<smiles>C1CC1</smiles>

(subschema)

Decision: Further investigation

Diagnostics :

1.

2.

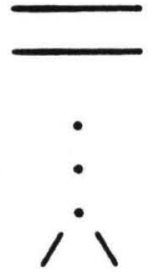

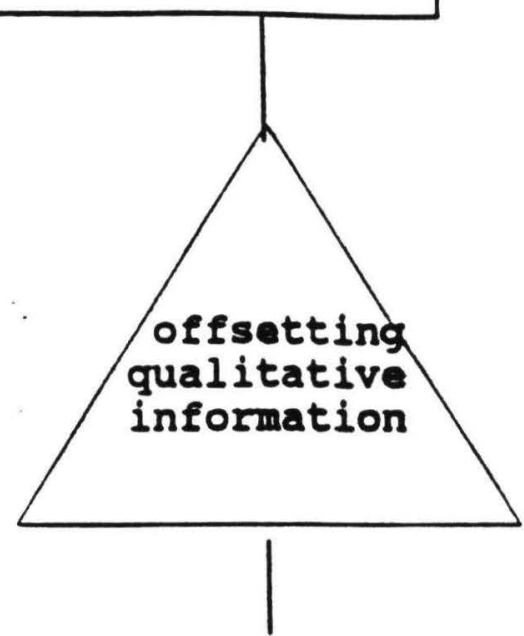

improved operations<smiles>C=CC</smiles>

(subschema) Decision: Unqualified opinion

Diagnostics:

1. Sales up 10 t

2. Sold unprofitable division<smiles></smiles>

Figure 1

Diagram of Traversing Case-Based Memory 


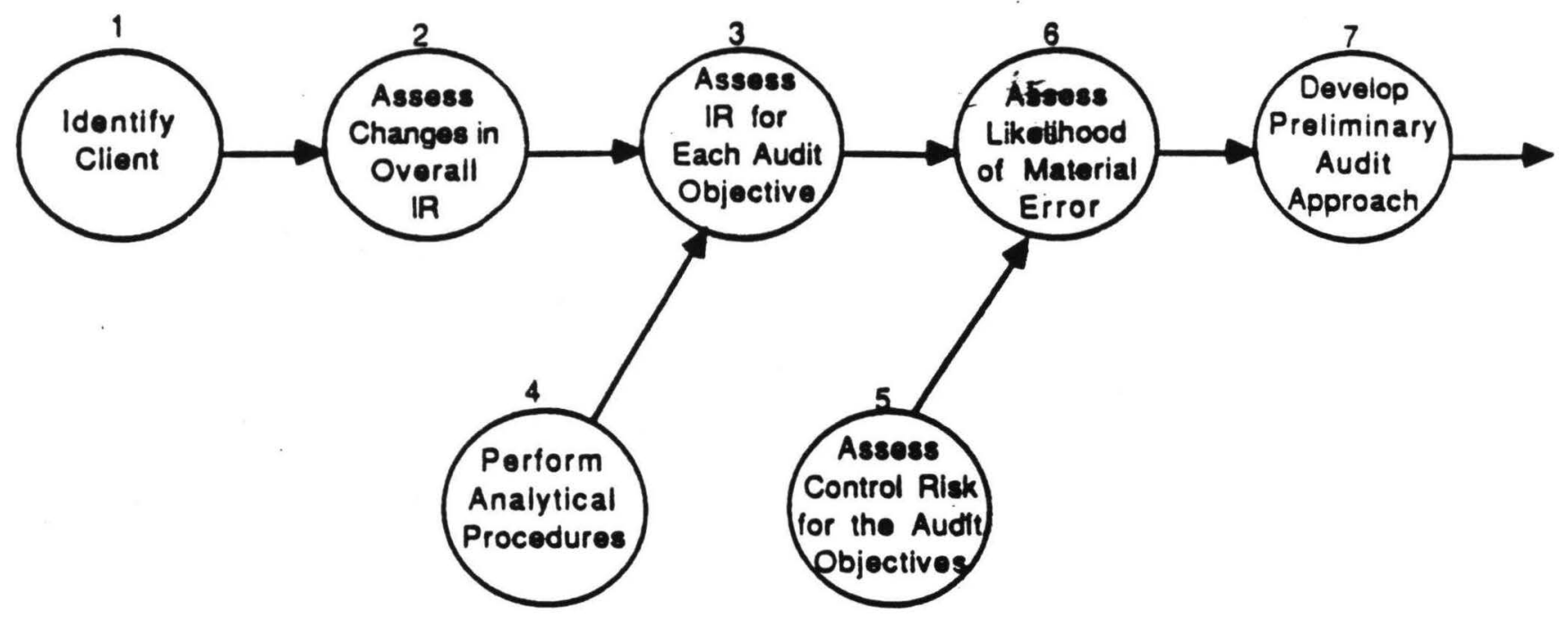

Figure 3 


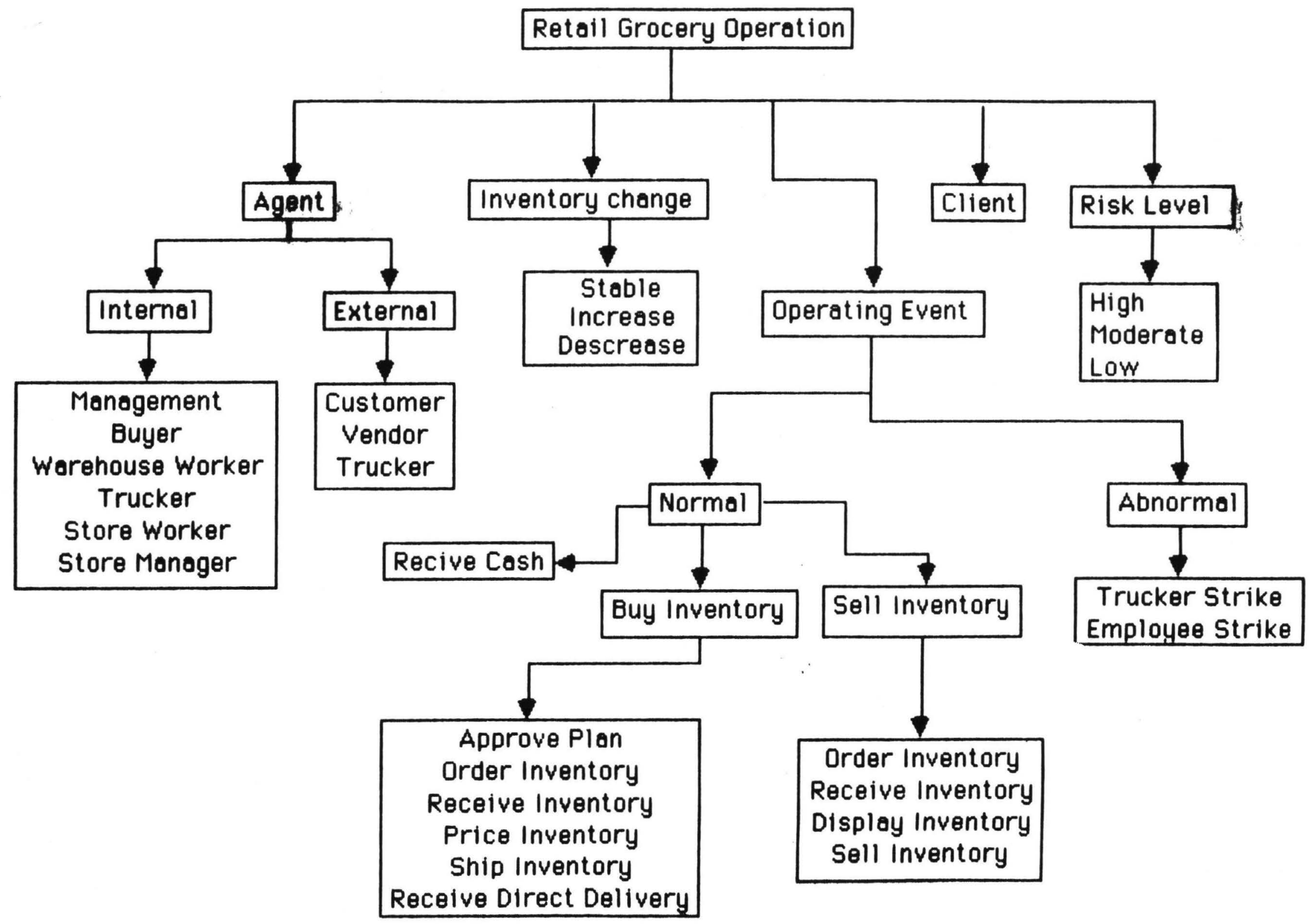

Figurer MOP Hierorchy 